\title{
Answering implicit questions: the case of namely*
}

\author{
Scott AnderBois \\ Brown University
}

\author{
Pauline Jacobson \\ Brown University
}

\begin{abstract}
Though several prior works use English namely as evidence for the semantics of other elements, its own syntax and semantics have been mostly unexamined. In this paper, we focus on two central questions which we claim to be interrelated. First, what is the semantic contribution of namely? Second, how does namely combine with the surrounding material compositionally to produce appropriate overall sentence meanings? Given the apparent similarity of namely to fragments and Sluicing, one answer suggested in previous literature (e.g. Onea \& Volodina 2011, Weir 2014, Ott 2016) is that an example like Someone coughed, namely Bill. involves deletion of silent linguistic material ... Bill eoughed. Here, we argue against this idea, arguing that namely introduces an answer to an implicit specificational question combining with its complement (i.e. Bill in the above example) directly, similar to Qu-Ans analysis of fragments (Groenendijk \& Stokhof 1984, Jacobson 2016).
\end{abstract}

Keywords: ellipsis, fragments, implicit questions, Sluicing, specification

\section{Introduction}

One of the central questions in the syntax-semantics interface is how the grammar treats cases where a propositional meaning emerges from uttering a subsentential bit of language. For example, fragments like 'Bill' can be answers to explicit questions as in (1) and also to implicit questions, as in (2). In this paper, we aim to expand this debate through detailed analysis of an analogous but quite underexplored case study: the use of namely. Fragments with namely are possible in answers to implicit questions, (2b), as well as - more commonly - within a single speaker, (3).

(1) a. A: Who (just) coughed?

b. B: Bill.
a. A: Someone coughed.
b. B: Yup, Bill. // Yup, namely Bill

(cf. Weir 2014)

* Our heartfelt thanks to the organizers, anonymous reviewers, and participants at SALT 28 for their comments and feedback. Thanks also to Matt Barros and Michael Yoshitaka Erlewine for more detailed discussion of aspects of the paper. 
Answering implicit questions: the case of namely

(3) Someone did fabulously in semantics, namely Samantha.

For explicit question answer pairs like (1), there have been two main types of approaches in prior literature:

Clausal ellipsis: In (1) - B's answer is at some level of structure a full sentence, with ellipsis: Bill coughed. ～(e.g. Morgan 1973, Merchant 2004)

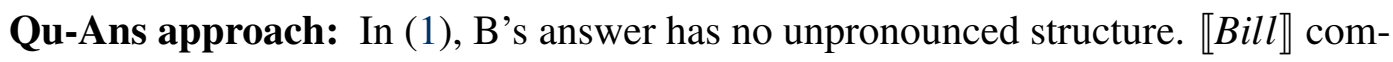
bines with a function derived from (or, in some accounts, equivalent to) the semantics of the question to yield the relevant proposition. (e.g. Groenendijk \& Stokhof 1984, Ginzburg \& Sag 2000, Jacobson 2016)

Since namely occurs with fragments in a partially overlapping set of environments, the same fundamental question arises: does namely arise from clausal ellipsis or should the Qu-Ans analysis be extended to this case? Beyond this, the cases of namely which have received the bulk of the attention in previous literature are ones like (2b) and (3), which have an indefinite in the antecedent material, thus giving the impression that namely parentheticals are quite similar to Sluicing.

Our main claims are as follows. Despite the superficial connection with Sluicing and other fragments, namely always introduces an answer to a question which is implicit and specificational. ${ }^{1}$ While ellipsis under identity fails to produce a suitably specificational semantics, the Qu-Ans analysis can be naturally extended to cover fragments with namely. An attempt to save ellipsis based on a non-identical specificational sentence (e.g. 'It is X.') is semantically viable, but we argue that such an approach would require a complex set of ad-hoc constraints on the complement of namely in addition to requiring obligatory ellipsis.

The road map for the rest of the paper is as follows: $\$ 2$ discusses several problems for full clausal ellipsis under identity; $\$ 3$ compares the implicit questions namely addresses with those of Sluicing, arguing that only the former are specificational; §4 extends the Qu-Ans approach to namely; 55 shows how specificational semantics emerges from this semantics and accounts for several seemingly aberrant cases; $\S 6$ argues that non-identity-based elliptical alternatives offer no advantage over the present approach and have several disadvantages; $\$ 7$ concludes.

1 The observation that namely introduces 'specificational' material is not novel to the present paper. Among others, Onea \& Volodina (2011) and Ott (2016) make this same observation. Despite that, however, they do not incorporate this observation into their analyses; both argue for the clausal ellipsis analysis shown above in which the full semantics of the namely fragment does not directly make a specificational contribution. Our analysis differs from these in proposing that the namely complement is the answer to a specificational question (i.e., not the question who coughed? but rather a question which is paraphrased more accurately as something like who was that person? 


\section{Problems for full clausal ellipsis under identity}

The question of how the complement of namely contributes its propositional information has not been widely studied, but recent accounts (Onea \& Volodina 2011 for the corresponding German case of nämlich, Weir 2014, Ott 2016) propose full clausal analyses with ellipsis under identity: ${ }^{2}$

a. Speaker A: Someone coughed.

b. Speaker B: Yup, namely Bill eoughed.

Speaker A: Someone coughed, namely Bill eoughed.

This would make the requisite identity condition similar to that needed for Sluicing under an ellipsis analysis of the latter. Notice that recent ellipses analyses of Sluicing require not only some sort of syntactic identity to an overt antecedent, but it has also been argued to require reference to implicit questions (Ginzburg \& Sag 2000; AnderBois 2014). At first glance, then, it appears that a clausal analysis like that above requires nothing additional beyond what is needed for Sluicing (under an ellipsis analysis of the latter). An additional benefit to subsuming the conditions for namely to those needed independently for Sluicing centers on the contrasts in (6). Thus AnderBois (2014) notes that Sluicing is impossible in (6b) because the first clause does not raise the appropriate question; namely is similarly impossible here:

a. Someone passed the course, \{namely Samantha/and I know who\}.

b. It's not true that no one passed the course, \{*namely Samantha/*and I know who\}

(cf. AnderBois 2014 for Sluicing case)

But the conclusion that the conditions for namely ellipsis can be subsumed to those for Sluicing ellipsis is too hasty; there are several problems with this. First, the putative full clausal variant for namely does not always have the right semantics:

(7) Fred scaled the tallest building in the world, namely Burj Khalifa.

The primary import of the namely part is not to tell us what building Fred scaled (though it indirectly does tell us this) but to specify what the tallest building is. Second, since the full clausal variants with namely are ungrammatical (unlike in Sluicing), ellipsis would thus have to be obligatory (see Jacobson (2009) for (8a)):

2 Working on German nämlich, Onea \& Volodina (2011) suggest that some kind of nonclausal analysis is also compatible with their observations, but argue nonetheless for the full clausal analysis of the sort shown in (4-5). However, although many of the observations we make are noted in this and other works in German cited therein, the question he uses to combine with the complement of namely is not a specificational one, so our analysis is not the same as his. We should also mention that German nämlich - which is their focus - has a use that English namely does not have. In all other respects, though, the facts they report for nämlich are the same as English namely; this is relevant for our discussion in $\S 6$. 
Answering implicit questions: the case of namely

(8) a. John knows who coughed, namely Bill /*namely Bill coughed.

b. Someone coughed, namely Bill/*namely Bill coughed.

Third, namely can be licensed in cases where no specific overt antecedent is plausible, as in (9), making it difficult to see how identity-based ellipsis can work.

(9) Scenario: I know that my roommate Sarah is applying to graduate schools, and I come home to see her popping open a bottle of champagne.

a. Me: A graduate acceptance?

b. Sarah: Yup, namely NYU!

Fourth, the elements that license namely differ significantly from those licensing Sluicing; we now turn to this in detail.

\section{Sluicing and namely: different implicit questions}

Basic examples with namely in previous literature often have indefinite antecedents, as in (2b) and (3), which might give the impression that namely and sluicing may be used in similar sets of environments. Beyond just being understudied, one likely reason for this is that namely has often been used to diagnose epistemic or freechoice inferences (e.g. by Alonso-Ovalle \& Menéndez-Benito (2010), Condoravdi (2015)), where ordinary indefinites have served as controls. For example, in the literature on -ever free relatives, the infelicity of namely has been used to distinguish epistemic/free choice readings from other indifference readings. While the contrast between indefinite and free-choice antecedents may suggest that namely has a similar distribution to Sluicing, a closer looks shows their distributions to be quite different.

First, whereas Sluicing prototypically relies on existential/indefinite antecedent material, namely readily allows for definite antecedents. In particular, definite descriptions whose definiteness is achieved via uniqueness, rather than familiarity, readily serve as hosts for namely, as in (7) and (10-11). ${ }^{3}$ In contrast, as seen in (10-11), corresponding Sluices are consistently degraded (as are non-elliptical fullclausal controls in many cases). One subcase discussed in previous literature are maximal/definite free relatives like (11), which Condoravdi (2015) argues allow for namely (following Dayal (1997), upon whose original example (11) is based).

3 We leave it to future work to explore in more details the potential predictions and ramifications of this distinction. One case where this generalization makes a clear prediction is for languages which morphosyntactically distinguish uniqueness and anaphoric definites (see, e.g. Schwarz (2009), Jenks (2015)). For example, Schwarz (2009) argues that German preposition-article contractions (e.g. zum 'to the') encode uniqueness, while uncontracted forms (e.g. zu dem) encode familiarity/anaphoricity. We therefore make the clear prediction that only the former should be compatible with nämlich 'namely', presuming that it is similar to English namely in relevant respects. 
(10) Fred scaled the tallest building in the world, \{ namely Burj Khalifa / *and I'll tell you which/what .

(11) I ate what Mary cooked, \{ namely ratatouille / *but I don't know what \}.

While uniqueness-based definite descriptions represent a case where namely works but Sluicing doesn't, we also find the opposite: i.e. cases where only Sluicing works. One such case is what have come to be known as 'sprouting', i.e. cases in which the elliptical question relates semantically to the prior material either as an adjunct or implicit argument. As seen in (12), parallel examples with namely are typically not possible (though see $\$ 5$ for discussion of an apparent counterexample).

a. Sharon was murdered, \{but I don't know by whom/*namely by Charles $\}$.

b. Juan celebrated his graduation, \{ but I don't know where/ *namely on the beach\}.

The second case where Sluicing is possible but namely is not is with disjunctive antecedents, as in (13a). Disjunctions pattern with indefinites in serving as antecedents for Sluicing (as discussed by AnderBois (2014)), but corresponding cases of namely are ill-formed. Their infelicity is all the more puzzling since indefinites with domains explicitly restricted to the same set of options are markedly better. We set aside the case of disjunction here, as we believe it tells us more about the nature of disjunction than it does about namely (see $§ 7.1$ for further discussion).

a. We'll hire Sally or Ted, \{ and I know which/*namely Sally

b. We'll hire one of Sally and Ted, namely Ted.

A somewhat more complicated case, first discussed by Jacobson (2009), is presented by embedded questions. First, the situation with Sluicing itself remains is complicated to begin with. ${ }^{4}$ Romero (1998) claims that embedded wh-questions can license Sluicing provided that the larger clauses containing them meet a focus condition by contrasting in some way. This claim is illustrated by examples with contrasting wh-phrases and contrasting subjects, (14a-14b). In apparent contrast to this generalization, however, a difference in the question-embedding verb itself does produce a similarly felicitous example, as seen in (14c). We leave it to future work to example the Sluicing data in more detail, concluding here only that embedded questions can only serve as antecedents for Sluicing under limited conditions.

a. We know how many papers this reviewer has read, but we don't know which ones.

Chung, Ladusaw \& McCloskey 1995

4 Thanks for Matt Barros for discussion of the Sluicing data in this area and analytical issues they raise. 
Answering implicit questions: the case of namely

b. We know how many papers this reviewer has read, but THEY don't know how many.

Romero 1998

c. \#? We don't know how many papers this reviewer has read, but we wonder how many.

Turning to namely, we find that examples with namely and embedded questions are impeccable, even when corresponding Sluices are infelicitous, as in (15). While there may be a temptation to attribute the ungrammaticality of the Sluicing example to a principle such as Max-Elide, this is not possible here since there is no larger elliptical competitor: ... he himself hasn't has a different meaning, and Null Complement Anaphora (i.e. ... he himself has not figured out) is not grammatical. ${ }^{5}$

(15) John couldn't sleep. His therapist finally realized what was bothering him, \{namely, his fear of being fired/*but he himself has not yet figured out what

While namely is licensed by embedded questions even when Sluicing is not, embedded questions with namely are, however, not always possibleerent constraint. First, they depend on the lexical semantics of the embedding predicate, as seen in (16). Second, holding the predicate constant, we find that negated counterparts of otherwise impeccable examples are quite bad.

(16) *Isabel wondered who got an A on the test, namely Sally.

(17) John $\{$ has/*hasn't $\}$ figured out who I plan to give the prize to, namely Sally.

To summarize, then, we find that while overlapping in the cases which have been most discussed previously - indefinites and free-choice elements - the range of antecedents for Sluicing and namely differs substantially, as summarized in Table 1.

Having shown that Sluicing and namely differ substantially in the range of antecedents that license them, we turn now to explain the distribution of namely. Taking the embedded question data as a jumping off point, note that the felicitous uses of namely are those which also readily license an individual discourse referent (or are good in contexts where such a referent is already available), as seen in (18).

5 Note that the namely phrase in embedded questions such as (15) cannot attach to what and hence cannot be seen as a genuine 'appositive' (we recast the example using shorter material, to rule out the possibility that the ill-formedness is due to having material that is too heavy as an appositive):

(i) a. John figured out who I will give the prize to - namely Sally.

b. *John figured out who, namely Sally, I will give the prize to. 


\begin{tabular}{c|c|c}
\hline Antecedent & Sluicing & Namely \\
Indefinite & Yes & Yes \\
Free choice & No & No \\
(Uniqueness) Definite & No & Yes \\
Sprouting & Yes & No \\
Disjunction & Yes & No \\
Embedded question & Depends on prosody & Depends on semantics
\end{tabular}

Table 1 Summary of antecedents for Sluicing and namely

(18) a. John has figured out who I plan to give the prize to. She deserves it.

b. John hasn't figured out who I plan to give the prize to. ?*She deserves it.

c. Isabel wondered who got an A on the test. *?He will thank his tutor.

Returning then to (6) - which at first glance suggested a parallel with Sluicing - the explanations for the unacceptability of (6b) in the two cases are somewhat different. In particular, AnderBois (2014) argues that Sluicing is bad in this case because the double negation prevents the potential QUD (i.e. 'issue' in the sense of inquisitive semantics) from being made salient, while namely is unacceptable because it does not evoke a discourse referent. Indeed, this is a classic 'marbles' example of the sort attributed to Barbara Partee and discussed in Heim 1982 and subsequent work. Of course it is likely that these two observations about double negation are at some deeper level related, but they are not prima facie the same, and so we leave open here the questions of whether and how they are to be unified.

(19) further shows that the parallelism between namely and the licensing of a discourse referent extends beyond indefinites and definites to implicit arguments, doubly negated indefinites, and other 'sprouting'-like cases. ${ }^{6}$

a. Sharon was murdered. *He was quite scary.

b. It's false that no one passed the course. *She was a terrific student all semester.

Whereas Sluicing requires a salient question or issue in prior discourse, for namely, then, we claim that it is the licensing of an individual discourse referent which is required. This generalization is spelled out informally in (20). Note that this also extends to the graduate acceptance example in (9), where a pronominal reference to the school is quite acceptable (e.g. .. Yup, and it's one of the best

6 The one place the parallelism breaks down is in the case of disjunction. While we leave a detailed investigation of disjunction to future work, see $\$ 7$ for arguments that the infelicity of disjunction with namely is due a conflict between specification and the felicity of conditions of disjunction in general. 
Answering implicit questions: the case of namely

school for sociolinguistics!). Conversely a minimally different case with no prior linguistic material of any kind such as one where the speaker just sees the roommate popping the cork on the champagne bottle neither provides a discourse referent for a school nor allows for the use of namely.

(20) Namely generalization: namely is licensed if and only if (i) there is material in the preceding discourse which supports a discourse referent, and (ii) the fragment serves to further specify that discourse referent.

The basic insights it captures are very similar to those expressed in the few recent works which discuss namely such as Onea \& Volodina 2011 and Condoravdi 2015. However, these works each focus more on one half of the generalization than the other because of the specific empirical focus they have. Onea \& Volodina's (2011) empirical focus is on German nämlich, which has a variety of non-specificational uses as well and so while the authors explicitly acknowledge the specificational nature of cases like the ones here, the need for a discourse referent to be specified is backgrounded in their discussion since German nämlich, unlike English namely, does have certain uses where no such discourse referent is required. ${ }^{7}$

Condoravdi (2015), on the other hand, proposes essentially the same generalization as in (20), but based solely based only on data from plain and ever free relatives. As such, her discussion focuses on the availability of discourse referents, with little discussion of the role that specification plays in determining the distribution of namely (e.g. the infelicity of namely with proper names and strongly familiar/anaphoric definites). By considering a broad range of different (potential) antecedents for namely, we hope to have shown that both parts of the generalization have important roles to play and that together, they account for the whole range of (potential) antecedents for namely.

Having presented a generalization about the distribution of namely, we turn now to develop a compositional analysis of namely that captures it. Condoravdi 2015 is a paper about free relatives and since its discussion of namely is a side note in this other endeavor, does not develop an account of the compositional syntax/semantics of namely beyond the generalization. Onea \& Volodina (2011), on the other hand, propose for nämlich an ellipsis based account of the sort we have argued against above in $\$ 2$. While they claim that "not much seems to hinge on this", the argue we make here is precisely the opposite - that careful consideration of the specificational semantics of namely and the conditions under which it occurs obliges a non-elliptical account (see $\$ 6$ for further discussion).

7 Moreover, while they do talk in various places about English namely, their analysis is quite explicitly an analysis of German nämlich and they also are careful to note that "There is a whole class of what we wish to call specificational particles, which have hardly been studied, and to which the analysis of nämlich should extend". 


\section{A Qu-Ans implementation which accounts for this generalization}

We have seen that namely introduces the answer to an implicit specificational question about a discourse referent, and that a specificational question is not the same as the implicit question relevant for Sluicing. Moreover, the question must be implicit; namely cannot introduce an answer to an explicit question:
A: Who coughed?
B: *Namely, Bill.

We return to this below.

We are now in a position to extend the Qu-Ans analysis to the case of namely. Recall that the Qu-Ans analysis of the dialogue in (22) relies on applying the function in (23a) with the answer in (23b) to give the proposition in (23c):

Speaker A: Who coughed?

Speaker B: Bill
a. $\lambda x[\quad$ coughed $\rrbracket(x) \quad]$

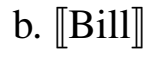
c. $\llbracket$ coughed $\rrbracket(\llbracket$ Bill $\rrbracket)$

The question then arises as to what contributes the function in (23a). Ginzburg \& Sag (2000) and Jacobson (2016) take this to actually be the meaning of main clause questions (Jacobson notes that this is true only of main clauses; embedded clauses can still have the Hamblin semantics). However, this will not do for the case of namely, because we assume that implicit questions are Hamblin sets. But this is not a problem: Groenendijk \& Stokhof (1989) (henceforth G\&S) show that there is a simple mapping from the function in (23a) to the relevant Hamblin question and vice-versa. Take any Hamblin question; for example the Hamblin question for (23a) is the set of propositions of the form $\llbracket \operatorname{coughed}^{\prime}(x) \rrbracket$ for all $x$ in some relevant domain D. Call that set HQ. Then the corresponding G\&S function (notated as GS(HQ) ) is the function $\mathrm{f}$ with domain $\mathrm{D}$ such that for all $x, \mathrm{f}(x)$ is a member of HQ. (HQ can similarly be derived from the relevant $f$; it is the set of propositions $P$ such that for all $x \mathrm{f}(x)$ is in $P$.) With this, the lexical entry for namely is as follows:

(24) Syntax: selects for any constituent of a certain category (this is some distinguished set of categories which are just those that also occur in short answers in general, in fronted position in Topicalization, etc.)

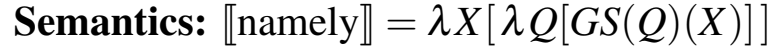

where $Q$ an implicit specificational question and $X$ is a variable ranging over any of the types that correspond to the categories of allowable complements of namely. 
Answering implicit questions: the case of namely

In prose, then, namely asks for some complement and an implicit question, derives the GS function from that question, and applies that function to the meaning of its complement.

This does leave open several interesting questions. Note first that as stated here, the fact that the question must be implicit is hardwired into the semantics of namely. This can be seen as a temporary fix; we would hope that this follows from something more general. The most hopeful possibility is that an overt question like that in (21) simply doesn't support the requisite specificational question. It does introduce a discourse referent as shown by the availability of subsequent anaphora:

A. $\mathrm{Who}_{i}$ did best on the final? B. I'll give you a hint - they ${ }_{i}$ are only a sophomore.

Nonetheless, it could well be that this doesn't support a specificational question about this discourse referent. Alternatively, it might be that there is a constraint to the effect that parenthetical material can never serve as 'at issue' content (see, e.g. the case of non-restrictive relatives discussed in Potts 2005, AnderBois, Brasoveanu \& Henderson 2015 and others and Onea 2016 for a broader discussion of this including German nämlich), and namely $\mathrm{X}$ tends to be a parenthetical. Unfortunately, this does not seem to cover all the cases; it by itself does not rule out Namely Bill as a bare answer to the question in (21) (nor is it clear that it is right to call it a 'parenthetical' in (4)). We thus leave this issue open for future research, being content to temporarily build the implicit question restriction in to the lexical semantics of namely. Second, this also means that the grammar must have access to the notion of a 'specificational' question (or, presumably also statement). We leave open the question of how to define this notion in detail.

One further contrast to note about the account proposed here is that while it makes reference to implicit questions, the necessary implicit questions are not QUDs in the sense of Roberts (2012). The account here relies on implicict specificational questions, which while salient in the discourse are not ones which the interlocutors were previously committed to resolving (a defining property of QUDs in Roberts's (2012) sense). In some cases, such as (26), the form of the antecedent material may implicate that the identity of the discourse referent is irrelevant or unknown, and therefore not a likely issue of conversation.

(26) I ate $\{$ something/what $\}$ Alejandro baked.

In contrast, although they note the specificational nature of namely in their prose, previous analyses like that of Onea \& Volodina (2011) that make use of non-specificational clausal sources also assume that the implicit question this content addresses is a QUD rather than an implicit specificational questions. While some works such as Ginzburg 1996 and Onea 2016 have developed more permissive 
notions of QUD that treat specificational implicit questions as a particular kind of QUD, this does not change the fact that the implicit questions namely addresses are only the specificational ones whose resolution is not a prior commitment of the speaker. We leave open the question of whether a notion of implicit question that unifies these two types is feasible or desirable for other purposes, but for namely the distinction is an important one.

\section{Specificational semantics emerges compositionally}

In the previous section, we have presented a proposal for the syntax and semantics for namely in which namely $X$ is a function taking a function derived from an implicit specificational question and returning the proposition obtained by applying that function to $\mathrm{X}$. That is to say, it returns true if and only if the complement of namely specifies a prior discourse referent, thereby answering the specificational question. While the internal composition of namely is therefore quite distinct from that of specificational copular clauses, we nonetheless ensure that semantic restrictions that hold of specificational copular clauses will also hold of namely by virtue of the fact that they must hold of the implicit question namely employs.

For example, Higgins (1979) describes at length the configurations of different kinds of elements such as demonstratives, proper names, definites, and indefinites that allow for specificational readings in copular clauses. For example, a proper name can stand in the specification relation to (k.e. can "specify") an indefinite noun phrase, (27a), while reverse is not possible, (27b). Beyond this Higgins (1979) argues that other grammatical phenomena such as wh-movement and ellipsis can be used to distinguish specificational copular clauses from other types. For example, as seen in (28), he shows that VP-Ellipsis distinguishes specificational copular sentences from non-specificational ones.

a. Jack Jones was a man I met yesterday.

b. *A man I met yesterday was Jack Jones.

a. My neighbor is Ellie, *my best friend isn't.

b. Ellie is my neighbor, Sally isn't.

As shown in (29-30), these same asymmetries are found with namely (see also Ott 2016 for similar observations):

a. *I got coffee with Jack Jones, namely a man I met yesterday.

b. I got coffee with a man I met yesterday, namely Jack Jones.
a. I'm bringing a pie to my neighbor, namely Ellie.
$\checkmark$ Spec
b. *I'm bringing a pie to Ellie, namely my neighbor. 
Answering implicit questions: the case of namely

Beyond this, Higgins (1979) shows that specificational copular clauses are possible with a wide variety of different syntactic categories for which a transformational analysis is not feasible, as in (31). Once again, we see that analogous examples with namely are possible in (32).

a. Mitka's (silliest) fear is of the left side of the bridge.

b. They told me that that what Mary was going to do was give the dog to John.

(32) a. Mitka has a silly fear, namely of the left side of the bridge.

b. They told me what Mary was going to do, namely give the dog to John.

Note that examples like (32a) appear at first blush like they might be examples of 'sprouting' uses of namely and therefore inconsistent with the generalization in §3. In particular, it may seem that of the left side of the bridge would be a complement to fear. Comparing this case with the ungrammatical 'sprouting' cases, repeated in (33), we see a clear difference. Whereas the apparent sprouting in (32) have specificational copular counterparts in (31), the ungrammatical 'sprouting'-like cases like (33) plainly do not, as seen in (34).

(33) a. Sharon was murdered, \{but I don't know by whom/*namely by Charles .

b. Juan celebrated his graduation, \{ but I don't know where/ *namely on the beach\}.

(34) a. *Sharon was murdered is by Charles.

b. *Juan celebrated his graduation is on the beach.

Whereas Sluicing allows for 'sprouting' examples regardless of where there is a specificational copular counterpart, namely only allows for this in the cases like (32a) where a specificational copular counterpart is possible. As discussed above, this sort of pattern provides a knockdown argument against the namely material arising from a full clause silenced under identity, as opposed to a non-specificational copular clause. Whereas the possibility of a non-copular counterpart is at least correlated with the grammaticality of Sluicing (though see van Craenenbroeck 2010, Barros 2014 for arguments that this is not always so), for namely it is only the existence of a specificational copular counterpart which is important.

While we have shown that the potential for namely fragments is related to that of specificational copular clauses, this of course does not mean that namely fragments arise from non-pronunciation of parts of a covert specificational copular clause. Rather, the account we have developed relies on the semantic notion of specification, which is itself what determines both the use of namely fragments and as Higgins (1979) argues, the properties of specificational copular clauses. While we therefore 
do not have a similarly knockdown argument against an approach relying on ellipsis with specificational copular clauses as sources, we show in the next section that such an approach does not buy anything over ours and requires fairly unusual additional assumptions to be made.

\section{Could ellipsis be saved?}

So strong is the desire to derive all propositional content of short utterances from full sentences, that several people (including two anonymous SALT reviewers) have suggested ways to account for our generalization using ellipsis. These attempts require abandoning ellipsis with an identity condition (as in the full clausal ellipsis analyses shown in (4-5)), and instead derive these from the silencing of a constant such as $i t$ is $X$ or pro is $X$; the former is similar to proposals such as van Craenenbroeck 2010 to derive some Sluices from 'short clefts'. Before proceeding, let us unpack the possibilities a bit more. One is that the 'source' is pro is $X$ for 'pro' some pronoun picking up the relevant discourse referent, and is being specificational/identificational $b e$. This seems unlikely since a regular pronoun is generally not allowed in corresponding full cases (without namely - full cases with namely are always bad to which we return):

(35) A man coughed.

a. It was Bill.

b. \#He was Bill.

Instead, then, let us consider an analysis where it be is silenced; hence (5), for example is:

(36) Someone coughed, namely it was Bill.

But what is the analysis of the it was Bill clause itself? The use of the term 'short cleft' for similar cases in the Sluicing literature suggests that overt it be $X$ clauses themselves (as in (35a)) actually are full clefts with some material silenced:

It was Bill who/that coughed.

In the namely case, then, the wh-portion is silenced by the general process allowing 'short clefts', and the it be portion silenced by an additional mechanism (supposedly also alive in those cases in which Sluices are argued to be hidden short clefts).

But that can't be the right analysis of these so-called short clefts, because this simply reintroduces the problem of what licenses the silencing of the wh-portion. Consider again (38) with either the namely continuation or equally well with an overt it is and no namely: 
Answering implicit questions: the case of namely

(38) a. Fred scaled the tallest building, namely it is Burj Khalifa which/that is the tallest building.

b. ... it is Burj Khalifa which/that is the tallest building.

As seen in our earlier discussion of the clausal ellipsis theory, there is no possible identity condition which could support the ellipsis of which/that is the tallest building, so a literal cleft with silenced material cannot be the underlying representation of the it is $X$ clause.

Similarly, there could be no identity-based silencing analysis for cases like the graduation acceptance in (9). The underlying full cleft for Sarah's answer would have to be something like (39b-39c) or some other potential paraphrase, none of which will satisfy any kind of identity condition on ellipsis:

(39) Scenario: I know that my roommate Sarah is applying to graduate schools, and I come home to see her popping open a bottle of champagne.

a. Me: A graduate acceptance?

b. Sarah: Yup, namely it was NYU that I got inte!

c. Sarah: Yup, namely it was NYU that accepted me!

This leaves us with the conclusion that 'short cleft' is a misnomer (at least for these cases), but there are perfectly viable alternative analyses of overt It was Bill cases as in (35a). We will not spell out all the full details here nor the full set of possibilities, but let us assume that $i t$ is a pronoun picking up some discourse-salient object that can be paraphrased as 'the identity of the person who coughed', and be again is the specificational be. Or, perhaps it is anaphoric to the implicit question, and the full construction has the question/answer semantics of specificational sentences put forth in Ross 1985 and Schlenker 2003. ${ }^{8}$

Let us see what it would take to formulate such an analysis. First, we need a rule allowing for the silencing of a constant of the form it be $X$ where is is the specificational be. A believer in "Sluicing from short clefts" might argue that this is independently motivated for the Sluicing case - but our data reveals a heavy caution for that analysis of some Sluices. For, if ellipsis of it be is generally allowable in Sluicing, then there is no explanation for the different distribution of namely and Sluicing. For example, there is no reason why (11) should be bad in the Sluicing

8 But beware of a potential circularity in relying on those analyses. For they derive the answer portion of what they analyze as a question answer pair analysis of specificational sentences as a full clause. This, then, would simply reintroduce all of the same problems about satisfying an identity condition. While we do not necessarily reject a 'hidden question/answer' analysis for some specificational sentences, we do not derive the answer itself from a full clause, but rather rely on the Qu-Ans analysis, avoiding this problem. 
case (see $§ 7.2$ for discussion). Second, we still need the grammar to access the notion of a specificational sentence as this applies only with be of 'specification'.

Third, this places quite a heavy burden on the complement of namely: it is only allowed to take a complement of the form it be ${ }_{S P E C} X$. It is rather unusual for a lexical item to select such details about the inner makeup of its complement (compare this to our syntactic analysis of namely). Semantically, it presumably is the identity function on implicit specificational questions, or implicit questions about the identity of some discourse referent. We leave open exactly what restrictions would need to be build in on the domain of this identity function, but we can note that here too something will be needed to ensure that namely is possible only with material that addresses an implicit question. Note that it is $X$ is a perfectly good answer to an explicit question as in (40); it is only with namely that this would be blocked:

A: Who coughed? $\quad$ B. It was Bill. / Namely, it was Bill.

Moreover, this analysis has no advantage over ours with respect to certain matching effects that we have not yet dealt with. There are some preposition matching effects in English which are complex and so space precludes a discussion of these, but let us consider case matching in the corresponding German case of nämlich. Ott (2016) points out that these show the same kind of case matching effects found in Sluicing; we assume that the analysis of nämlich is similar to our analysis of namely (modulo the fact that nämlich has an additional use discussed in Onea \& Volodina 2011; otherwise their distribution seems quite parallel). Our analysis has no account of this; the hope would be that something like the direct matching approach of Ginzburg \& Sag (2000) for Sluicing would extend here. ${ }^{9}$ But the silencing of $i t$ be also provides no such account since matching is normally not required in such cases (see Merchant 2001 for discussion of this with respect to the Sluicing from short cleft analyses). So nothing is to be gained by this kind of ellipsis analysis with respect to matching phenomena. ${ }^{10}$

Finally, and most strikingly, unlike for most cases of so-called ellipsis, the silencing is obligatory, since the following is completely bad ${ }^{11}$ :

Someone coughed, *namely it was Bill.

9 Groenendijk \& Stokhof (1984), Ginzburg \& Sag (2000), and Jacobson (2016) all provide an account of Case Matching of direct question-answer pairs under the Qu-Ans analysis. Unfortunately, that account will not extend directly to the case of implicit question-answer pairs, as the interested reader can verify.

10 Ott (2016) gives other rather common 'connectivity' arguments for ellipsis in a range of 'appositives' including namely - arguments based on, e.g., reflexive distribution and 'bound variable' connectivity. These arguments have been answered for similar cases at least as early as Jacobson 1994 and Sharvit 1999; see Jacobson 2016 for discussion concerning the fallacy of these kinds of arguments in general.

11 Matt Barros (p.c.) suggests to us that the 'source' could be not what we have, but rather (i) with parenthetical intonation, which he reports to be grammatical in his judgment. 
Answering implicit questions: the case of namely

And note that it is not enough to just require silencing of it was but again the lexical entry for namely will require that it be $X$ be the complement and nothing else with specificational semantics, since (42) and other more lengthy specificational options are equally bad:

a. Someone coughed, *namely the person who coughed was Bill.

b. Someone coughed, *namely the identity of the person who coughed was Bill.

In sum, there is no obvious advantage to an ellipsis analysis and several disadvantages. The grammar still requires access to the notion of specification; it requires access to questions which are only implicit, the syntactic portion of the lexical entry for namely is considerably more complex than in our theory; the semantics might be simpler but this is not clear since the 'implicit question' part needs to be built in somewhere; this requires a rule of silencing (not independently motivated) and some principle to make it obligatory here. This seems to be a lot of trouble merely to preserve the intuition that all fragments which give rise to propositional inferences are underlyingly clausal.

\section{Conclusions and future directions}

In this paper, we have presented a detailed examination of the syntax and semantics of fragments with English namely. What little previous literature there is on namely (and related words like German nämlich) has analyzed such fragments as being the results of deletion under identity of a full clause. While adopting some of the insights of this literature - most notably, Onea \& Volodina's (2011) claim that namely fragments serve a specificational function - we have argued against the viability of a deletion under identity-based approach. Specifically, we have argued that the putative full clausal sources are not themselves grammatical and even if they were, do not produce the necessary specificational semantics.

Instead, we have proposed an account on which namely does not rely on deletion under identity with some prior linguistic material, but rather, composes directly with the surface fragment. In particular, we have extended the Qu-Ans approach to other kinds of fragments, claiming that namely composes with the fragment and (the

(i) Someone coughed, it was, namely, Bill

In our judgments, this full clausal version is not possible and we have been unable to find naturally-occurring examples of this sort, and so we leave to future work to determine whether such full-clausal sentences are possible for some speakers. Setting aside these concerns about the data itself, this potential source still leaves open the question of how to license the ellipsis from (i) and additionally requires an explanation for the intonational difference with the elliptical forms. 
G\&S function variant of) an implicit question specifying a prior discourse referent. The account therefore predict the core empirical generalizations we have made for namely: namely is licensed if and only if (i) there is material in the preceding discourse which supports a discourse referent, and (ii) the fragment serves to further specify that discourse referent by addressing this implicit specificational question.

Similar to accounts of Sluicing that rely on (potential) QUDs or related notions (e.g. Ginzburg \& Sag 2000, AnderBois 2014), the account relies on the idea that the compositional semantics must have access to implicit questions. However, despite this commonality, the nature of the implicit questions needed in the two cases is quite different in ways that shape the range of contexts in which each is possible. For example, uniqueness-based definite descriptions and certain embedded questions both introduce discourse referents and therefore license namely, even when further specifying this discourse referent was not a salient issue in discourse. Sluicing, on the other hand, is not possible in these cases for precisely this reason (see below). On the other hand, there are cases such as sprouting with adjuncts, where a salient implicit question can license Sluicing, but no discourse referent is licensed and so namely is correspondingly impossible. All of this is to say that Sluicing and namely involve different sorts of implicit questions and correspondingly have quite different distributions. These differences have been underappreciated in previous literature in large part because the kind of antecedent material that has been most discussed - indefinites - introduce both a salient issue of the sort needed for Sluicing and a discourse referent in need of specification.

\subsection{The case of disjunction}

There is, however, one case we have seen where the parallel between the availability of discourse referents and the licensing of namely appears to break down: disjunctions such as (43), repeated from (13).

(43) We'll hire Sally or Ted, *namely Sally.

While there are many complex details about the conditions under which such 'external anaphora' is available (see Simons 1996 and references therein for discussion), disjunctions often license a discourse referent in subsequent discourse, as in (44). Even in cases where this is possible, however, namely remains quite infelicitous as we have seen. Another minimal pair is found in (45).

(44) We'll hire Sally or Ted, and they will sit at the desk over there.

(45) a. My father caught a trout or a seabass yesterday, *namely a sea bass.

b. My father caught a trout or a seabass yesterday and then gutted it in the sink. 
Answering implicit questions: the case of namely

Since our first condition for namely is met (material supporting a discourse referent), we tentatively conclude that it is the second condition that is the issue here, i.e. the ability for the discourse referent to be further specified. Concretely, it seems reasonable to assume that the semantics/pragmatics of disjunction generally is incompatible with specifications of the relevant kind since it requires in some way that both of the two disjuncts be live options in order to be felicitous. In essence, then, the hope would be that disjunction patterns together with free choice items like wh- + ever, which as discussed by Condoravdi (2015) and references therein, similarly resist further specification despite supporting discourse referents. We leave it future work to explore precisely why disjunction produces this effect (especially since ordinary indefinites do not).

\subsection{Implications for sluicing}

Finally, while not directly relevant to the analysis of namely per se, our study reveals two interesting facts/consequences for the analysis of Sluicing. First, the different distribution of material that licenses namely and Sluicing casts doubt on analyses of the latter which allows some Sluices to be elliptical for 'short clefts', assuming that by this is meant some sort of specificational material. Consider for example the case of the free relative in (46) which hosts namely but not a Sluice: (*I ate what she cooked, but I don't know what). But a full version with what it was is good:

(46) I ate what she cooked, but I don't (exactly) know what it was.

An advocate of "sluice from short cleft" might object to this argument by claiming that in the good (46) it is the referential pronoun it and not the it (presumably an expletive) that one finds in a 'short cleft'. While it is difficult to know (especially since it is not clear exactly what is meant by a 'short cleft') we can note that the full cleft is fine here too and so if the item it in so-called short clefts is the same as that item in full clefts, then (46) should have an analysis in which it is an expletive:

(47) I ate what she cooked, but I don't know (exactly) what it was that she cooked.

Again, then, there is no obvious reason why the putative short cleft source for Sluicing should be unavailable. Hence, just as it is unlikely that namely complements are elliptical for material of the form namely it is $X$, it is also unlikely that the complements of $w h$-words in Sluicing are elliptical versions of this kind of material. Second, we have introduced a new puzzle: why is it that embedded questions such as those discussed in Section 3 often do not license Sluicing (while some others do, see above discussion)? We note again that this is not due to MaxElide. We have no answer for this question, but as far as we know this has not been previously observed in the literature, so we conclude our discussion with the contribution of this new puzzle for Sluicing. 
AnderBois and Jacobson

\section{References}

Alonso-Ovalle, Luis \& Paula Menéndez-Benito. 2010. Modal indefinites. Natural Language Semantics 18(1). 1-31. doi:0.1007/s11050-009-9048-4.

AnderBois, Scott. 2014. The semantics of sluicing: beyond truth-conditions. Language 90(4). 887-926. doi:10.1353/lan.2014.0110.

AnderBois, Scott, Adrian Brasoveanu \& Robert Henderson. 2015. At-issue proposals and appositive impositions in discourse. Journal of Semantics 32(1). 93-138. doi:10.1093/jos/fft014.

Barros, Matthew. 2014. Sluicing and Identity in Ellipsis: New Brunswick, NJ: Rutgers dissertation.

Chung, Sandra, William Ladusaw \& James McCloskey. 1995. Sluicing and logical form. Natural Language Semantics 3. 239-82. doi:10.1007/bf01248819.

Condoravdi, Cleo. 2015. Ignorance, indifference, and individuation with wh-ever. In Epistemic Indefinites, 213-243. Oxford University Press. doi:10.1093/acprof:oso/9780199665297.003.0010.

Dayal, Veneeta. 1997. Free relatives and -ever: Identity and free choice readings. In Semantics and Linguistic Theory (SALT) 7, 99-116. CLC Publications. doi:10.3765/salt.v7i0.2787.

Ginzburg, Jonathan. 1996. Dynamics and the semantics of dialogue. In Language, Logic, and Computation, vol. 1, 221-237. Stanford, CA: Center for the Study of Language \& Information (CSLI), Stanford University.

Ginzburg, Jonathan \& Ivan Sag. 2000. Interrogative investigations. CSLI Publications.

Groenendijk, Jeroen \& Martin Stokhof. 1984. Studies on the semantics of questions and the pragmatics of answers: University of Amsterdam dissertation.

Groenendijk, Jeroen \& Martin Stokhof. 1989. Type shifting rules and the semantics of interrogatives. In Properties, Types and Meaning, vol. 2: Semantic Issues, 21-68. Kluwer. doi:10.1007/978-94-009-2723-0_2.

Heim, Irene. 1982. The semantics of definite and indefinite noun phrases: Amherst, MA: University of Massachusetts dissertation.

Higgins, Roger. 1979. The pseudo-cleft construction in English. Garland Publishing. Jacobson, Pauline. 1994. Binding connectivity in copular sentences. In Semantics and Linguistic Theory (SALT) 4, 161-178. doi:10.3765/salt.v4i0.2456.

Jacobson, Pauline. 2009. The short answer. and what it answers. Paper presented at 16th annual HPSG Conference, Göttingen, Germany.

Jacobson, Pauline. 2016. The short answer: Implications for direct compositionality (and vice versa). Language 92(2). 331-375. doi:10.1353/lan.2016.0038.

Jenks, Peter. 2015. Two kinds of definites in numeral classifier languages. In Semantics and Linguistic Theory (SALT) 25, 103-124. doi:10.3765/salt.v25i0.3057. 
Answering implicit questions: the case of namely

Merchant, Jason. 2001. The Syntax of Silence. Oxford University Press. doi:10.1007/s10988-005-7378-3.

Merchant, Jason. 2004. Fragments and ellipsis. Linguistics and Philosophy 27. $661-738$

Morgan, Jerry. 1973. Sentence fragments and the notion 'sentence'. In Issues in linguistics: Papers in honor of Henry and Renée Kahane, 719-751. University of Illinois Press.

Onea, Edgar. 2016. Potential Questions at the Pragmatics Semantics Interface. Brill Publishing.

Onea, Edgar \& Anna Volodina. 2011. Between specification and explanation. about a German discourse particle. International Review of Pragmatics 3(1). 3-32. doi:10.1163/187731011x561036.

Ott, Dennis. 2016. Ellipsis in appositives. Glossa 1(1). 1-46. doi:10.5334/gjgl.37.

Potts, Christopher. 2005. The Logic of Conventional Implicatures. Oxford University Press.

Roberts, Craige. 2012. Information structure in discourse: Towards an integrated formal theory of pragmatics. Semantics and Pragmatics 5(6). 1-69. doi:10.3765/sp.5.6.

Romero, Maribel. 1998. Focus and reconstruction effects in wh-phrases: Amherst, MA: University of Massachusetts dissertation.

Ross, J.R. 1985. The source of pseudocleft sentences. Handout of talk given at New York University, November 1985.

Schlenker, Philippe. 2003. Clausal equations (a note on the connectivity problem). Natural Language and Linguistic Theory 21. 157-214. doi:10.1023/a:1021843427276.

Schwarz, Florian. 2009. Two types of definites in natural language: Amherst, MA: University of Massachusetts dissertation.

Sharvit, Yael. 1999. Connectivity in specificational sentences. Natural Language Semantics 7. 299-339.

Simons, Mandy. 1996. Disjunction and anaphora. In Semantics and Linguistic Theory (SALT) 6, 245-260. doi:10.3765/salt.v6i0.2760.

van Craenenbroeck, Jeroen. 2010. Invisible last resort. a note on clefts as the underlying source for sluicing. Lingua 120. 1714-1726. doi:10.1016/j.lingua.2010.01.002.

Weir, Andrew. 2014. Fragments and clausal ellipsis: Amherst, MA: University of Massachusetts dissertation. 
AnderBois and Jacobson

Scott AnderBois

Brown University

Box 1821

190 Thayer St.

Providence, RI 02912

scott_anderbois@brown.edu
Pauline Jacobson

Brown University

Box 1821

190 Thayer St.

Providence, RI 02912

pauline_jacobson@brown.edu 